\title{
Microstructure-Property Relationship in Self-Crosslinked Non-Derivative Acetic Acid Lignin-Containing Polyurethane Membranes
}

\author{
Baojian Liu*, Zhongjin Li, Haihua Wang* \\ Key Laboratory of Auxiliary Chemistry \& Technology for Chemical Industry, Ministry of Education, \\ Shaanxi University of Science \& Technology, Xi'an, China \\ Email: 846779491@qq.com, wseaflower@126.com
}

Received 18 June 2014; revised 11 July 2014; accepted 10 August 2014

Copyright $@ 2014$ by authors and Scientific Research Publishing Inc.

This work is licensed under the Creative Commons Attribution International License (CC BY). http://creativecommons.org/licenses/by/4.0/

(c) (i) Open Access

\section{Abstract}

With the assistance of different solvents, self-crosslinked acetic acid lignin-containing polyurethane (LPU) membranes were synthesized. Compared with tetrahydrofuran and dioxane, $\mathrm{N}, \mathrm{N}$ dimethylacetamide with stronger polarity together with higher boiling point was demonstrated to be beneficial for preparing LPU particles of smaller size and enhanced binding force. It was also found that lignin domain can interpenetrate into polyurethane domain well with $43.3 \%$ lignin addition, resulting in enhanced phase mixing and better performance. In addition, relative homogeneous and smooth LPU membrane can be obtained with $2 \%$ TMP addition, while stress crack took place when TMP content was greater than $3 \%$.

\section{Keywords}

Polyurethane, Phase Behavior, Acetic Acid Lignin, Membrane, Microstructure

\section{Introduction}

The utilization of renewable biomass resources in polymer has received increased attention due to their potential for substitution of petrochemical derivatives [1] [2]. Lignin, as a nontoxic, low-cost and renewable biomass resource, has been considered to replace for some petrochemical products for a number of good causes, such as relying less on petroleum resources, decreasing environment pressure caused by non-biodegradable polymers [3] [4]. In the literature, there are many publications available in using ethanol [5]-[7], acetic acid [8] [9] and banana stem [10] [11] to dissolve the lignin in the lignocellulosic material. The lignin thus obtained has higher relative

${ }^{*}$ Corresponding authors.

How to cite this paper: Liu, B.J., Li, Z.J. and Wang, H.H. (2014) Microstructure-Property Relationship in Self-Crosslinked Non-Derivative Acetic Acid Lignin-Containing Polyurethane Membranes. Green and Sustainable Chemistry, 4, 162-174. 
amount of functional groups, better plastic behavior and processing performance [12] [13].

The high reactivity associated with lignin-based polyols makes them ideal for the synthesis of polyurethane (PU) [14]-[18]. For segmented PU, lignin has been extensively adopted as the thermal plastic elastomers because of their excellent mechanical and chemical characteristics [19] [20]. However, PU films prepared from the ethanol lignin (also known as Alcell lignin) and 4, 4'-diphenyl methane diisocyanate (MDI) by solution casting were very brittle [21], similar results were obtained by others [22]. This can be attributed to the aromatic nature of the hard segments of lignin and MDI, and the crosslinked structure. As a result, soft segment such as polyethylene glycol (PEG) [23] [24] can be introduced into the network to improve their thermal and mechanical properties. A maximum of 18\% Alcell lignin fraction was used to prepare PU [23]. A low loading level of lignin could enhance the strength and elongation. While a high lignin loading results in decreases in the toughness and other strength properties [25]. Therefore, the incorporation of high amount of lignin to synthesize lignin-containing polyurethane with good mechanical properties and water resistance is still a hot topic.

It is well known that the physicochemical properties of PU always depend on the morphology and phase behavior, while the morphology of PU relies on the state of compatibility and microphase segregation between the soft and hard segments [19]. Three important factors can influence the formation of the phase-separated microstructure of segmented PU block copolymers: block lengths, their chemical composition and thermodynamic miscibility between the hard and soft segments [26] [27]. The hard/soft segment miscibility can be attributed to hydrogen-bonds formed between the carbonyl groups of the soft segments and urethane amide groups in the hard segments [27]. Furthermore, the cross-link density, the relative rate of network formation of each component, the rate of phase separation and composition ratio can all influence the phase continuity and domain size [28]. In addition, the polar groups in lignin tend to produce aggregated domain, in which hydrogen bonding induces supramolecular characteristics [29] [30], which may change the microstructure of polyurethane.

The literature so far has focused on modification and properties of lignin-containing polyurethane, and most of them were carried out on ethanol-(Alcell) lignin, limited publications were available on the acetic acid lignin (AL) [31]-[34]. The acetic acid process has been reported to be an effective alternative method to delignify lignocellulosic materials to prepare pulp, and it is also demonstrated to be an environmentally friendly method [35] [36]. Organic acid lignin is an optimal feedstock for many value added products due to its lower molecular weight and high reactivity [37] [38]. As to the preparation for ethanol (Alcell) lignin-containing polyurethane, tetrahydrofuran (THF) was often employed as solvent [14] [39]. However, to our knowledge, there is no systematic study available. The motivation of this work is to provide fundamental insights of utilizing AL to prepare polyurethane membranes with good mechanical properties and water resistance for plastic or rubber application. Our previous study has suggested that the thermal stability can be enhanced with the addition of lignin and trimethylolpropane (TMP, as a crosslinking agent) [34]. In this study, we introduced AL as a renewable resource to prepare PU and determined the influence of solvent, AL and TMP content on the microstructure, phase behavior, mechanical properties and water resistance of the resulting lignin-containing polyurethane (LPU) membranes. Various complementary analytical techniques, such as Environmental Scanning electron microscope (ESEM), Dynamic mechanical analysis (DMA) and X-ray photoelectron spectroscopy (XPS) were used.

\section{Experimental}

\subsection{Materials}

The following reagents were used without further purification: methylene diphenyl diisocyanate (MDI), polyethylene glycol (PEG), trimethylolpropane (TMP), N, N-dimethylacetamide (DMAc); acetic acid, HCl, dioxane, diethyl ether, all of which were from Aldrich Chemicals; the acetic acid lignin (AL) was prepared in our laboratory.

\subsection{Preparation of AL}

Spruce wood chips were submitted to a treatment with $90 \%$ acetic-acid solutions (500 ml) catalyzed by small amount $(0.6 \%)$ of $\mathrm{HCl}(8.3 \mathrm{~g})$. The mixture was refluxed using a liquor/wood ratio equal to $5 \mathrm{~g} / \mathrm{g}$ for $3 \mathrm{~h}$. Lignin was dissolved in the spent liquor, which was then separated by filtration, and subsequently concentrated in a rotary vacuum evaporator at $60^{\circ} \mathrm{C}$. The $\mathrm{AL}$ was then obtained by diluting the above-obtained concentrated filtrate with deionized water (a dilution factor of 9 ) and filtrated. The procedure and the subsequent purification processes were given in an earlier paper [34]. 


\subsection{Preparation of LPU}

AL, TMP and PEG with different molecular weight were dissolved in solvent. MDI was added. The mixture was kept stirring in a water bath at $60^{\circ} \mathrm{C}$ for $2 \mathrm{~h}$. Then the temperature was increased to $70^{\circ} \mathrm{C}$, the reaction was continued for another $0.5 \mathrm{~h}$. The experimental conditions for preparing LPU are given in Table 1, as well as their tensile strength and water absorption. The experiment schemes and model of LPU without and with TMP were illustrated in Figure 1.

\subsection{Preparation of LPU Membranes}

After the polymerization, the solution was immediately poured onto a PTFE plate, which was allowed to dry at room temperature for 2 days and then at $100^{\circ} \mathrm{C}$ for $6 \mathrm{~h}$. After de-molding, the film was submitted to vacuum drying over phosphorous pentoxide for 5 days.

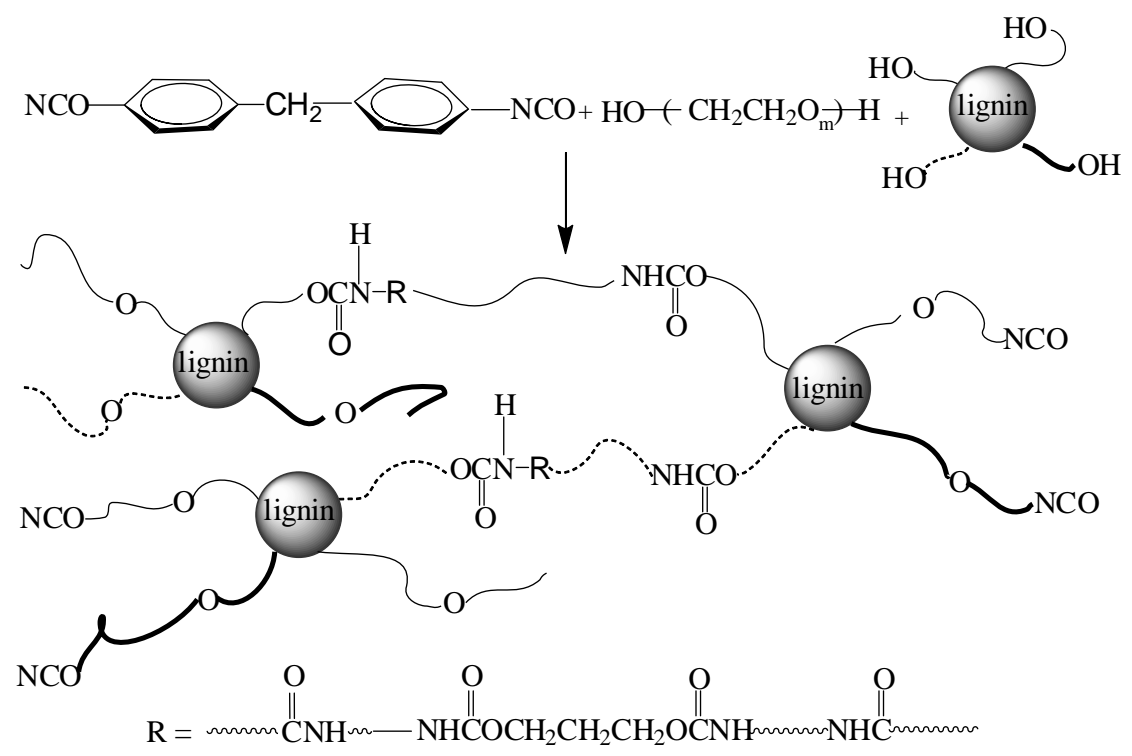

(a)

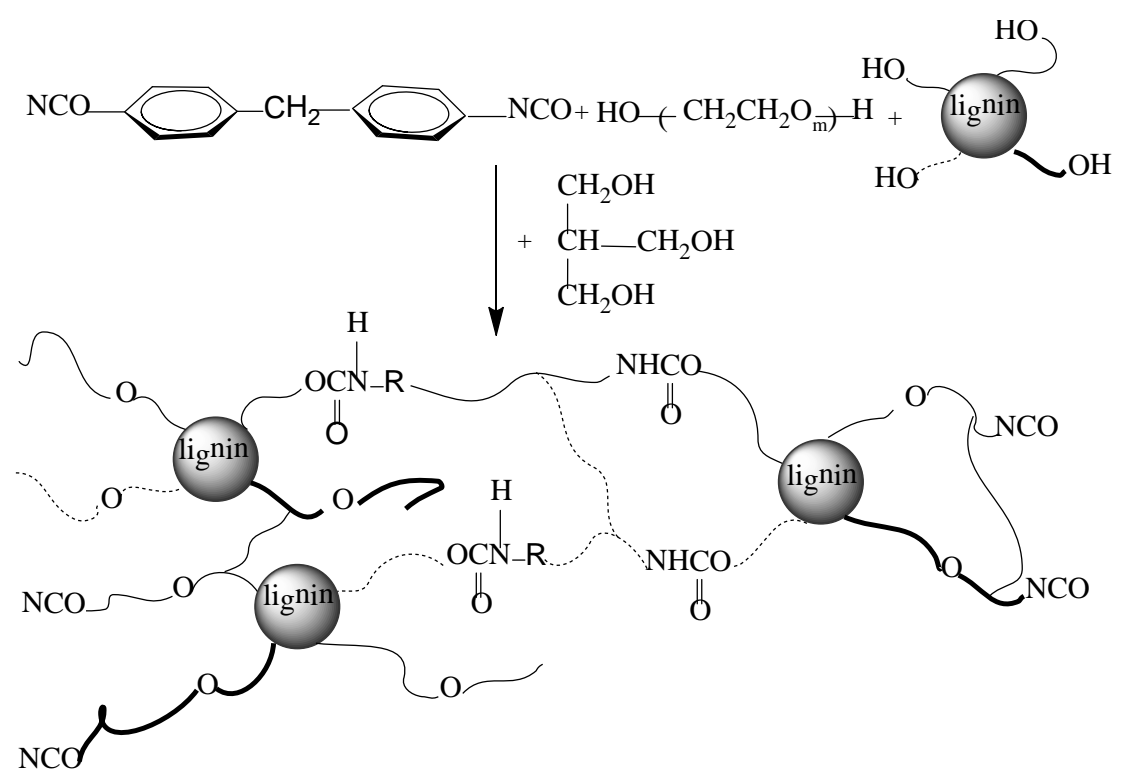

(b)

Figure 1. Experimental scheme and model of LPU (a) without TMP; (b) with TMP. 
Table 1. Composition of lignin-containing polyurethanes.

\begin{tabular}{|c|c|c|c|c|c|c|}
\hline Sample & $\begin{array}{c}\text { Molecular weight of } \\
\text { PEG }\end{array}$ & $\mathrm{n}(\mathrm{NCO}) / \mathrm{n}(\mathrm{OH})$ & Lignin/ $/{ }^{\mathrm{a}}$ & TMP $/ \%^{\mathrm{b}}$ & $\begin{array}{c}\text { Tensile } \\
\text { strength/MPa }\end{array}$ & $\begin{array}{c}\text { Water } \\
\text { absorption/\% }\end{array}$ \\
\hline $\mathrm{PU}$ & 1000 & $1.7: 1$ & 0 & 0 & 13.4 & 73.83 \\
\hline LPU1 & 1000 & $1.7: 1$ & $43.3 \%$ & 0 & 16.2 & 35.07 \\
\hline LPU2 & 1000 & $1.7: 1$ & $50.0 \%$ & 0 & -- & -- \\
\hline LPU3 & 1000 & $1.5: 1$ & $43.3 \%$ & 0 & 8.12 & 37.81 \\
\hline LPU4 & 1000 & $2.2: 1$ & $43.3 \%$ & 0 & -- & -- \\
\hline LPUP1 & 200 & $1.7: 1$ & $43.3 \%$ & 0 & -- & -- \\
\hline LPUP2 & 400 & $1.7: 1$ & $43.3 \%$ & 0 & -- & -- \\
\hline LPUP3 & 600 & $1.7: 1$ & $43.3 \%$ & 0 & -- & -- \\
\hline LPUP4 & 1000 & $1.7: 1$ & $43.3 \%$ & 0 & 16.2 & 35.07 \\
\hline LPUP5 & 1500 & $1.7: 1$ & $43.3 \%$ & 0 & 7.93 & 30.21 \\
\hline LPUT1 & 1000 & $1.7: 1$ & $43.3 \%$ & $1 \%$ & 18.8 & 23.63 \\
\hline LPUT2 & 1000 & $1.7: 1$ & $43.3 \%$ & $2 \%$ & 21.1 & 12.01 \\
\hline LPUT3 & 1000 & $1.7: 1$ & $43.3 \%$ & $3 \%$ & 14.1 & 14.10 \\
\hline LPUT4 & 1000 & $1.7: 1$ & $43.3 \%$ & $5 \%$ & -- & -- \\
\hline
\end{tabular}

${ }^{\mathrm{a}}$ With respect to PEG; ${ }^{\text {} W i t h ~ r e s p e c t ~ t o ~ t o t a l ~ m o n o m e r ~ m a s s . ~}$

\subsection{Swelling Test}

Samples of approximately $3 \mathrm{~mm} \times 3 \mathrm{~mm}$ were immersed in flasks containing dimethyl formamide (DMF) and allowed them to stand at ambient temperature. After 5 days equilibrium, samples were removed from DMF and patted with lint-free tissue paper to remove excess solvent, and the dimensions were measured again. The crosslink density $\left(\mathrm{mol} \cdot \mathrm{cm}^{-3}\right)$ of the NCO-OH bonds for each specimen was estimated using Equation (1) which was proposed by Flory and Rehner [12] [40].

$$
\frac{v_{c}}{V_{0}}\left(\mathrm{~mol} / \mathrm{cm}^{3}\right)=\frac{-2\left[v+\chi v^{2}+\ln \ln (1-v)\right]}{V_{1}\left(2 v^{1 / 3}-v\right)}
$$

where $v_{c}$ is the effective number of moles of crosslinked chains, $V_{1}$ is the molar volume of solvent, $\chi$ is the polymer-solvent interaction parameter, $v$ is the volume fraction of polymer in swollen gel $\left(v=V_{0} / V\right), V_{0}$ is the volume of dry polymer, and $V$ is volume of swollen gel at equilibrium.

In order to determine $\chi$ for our PU-DMF system, swelling tests were carried out $25^{\circ} \mathrm{C}, 30^{\circ} \mathrm{C}$ and $35^{\circ} \mathrm{C}$. From the temperature dependency of the swelling volume, $\chi$ value was obtained from Equation (2) [21]. In the present study, the polymer-solvent interaction parameter $(\chi)$ was determined to be 0.49 .

$$
\frac{\partial \ln v}{\partial \ln T}=\frac{-3 \chi(1-v)}{5(1-\chi)}
$$

\subsection{Characterization}

Environmental scanning electron microscope (ESEM) was carried out on a Hitachi SU-70 SEM. The sample surface was coated by carbon to remove the charge effect.

The temperature dependence of dynamic mechanical properties was conducted using an America TA Q800 dynamic viscoelastometer at an operating frequency of $1 \mathrm{~Hz}$ from $-110^{\circ} \mathrm{C}$ to $200^{\circ} \mathrm{C}$ at a heating rate of $3^{\circ} \mathrm{C} \cdot \mathrm{min}^{-1}$.

The tensile strength of the films was measured on a multifunctional electronic strength tester TS 2000-S (Scientific and Technological et. Taiwan). Tensile test bars $\left(5 \times 70 \mathrm{~mm}^{2}\right)$ were cut from hybrid films of $0.4-0.7$ mm thickness. The standard tensile testing was performed by following ASTM 412-83. 
Angular dependent X-ray photoelectronic spectroscopy (XPS) was performed on a Perkin-Elmer physical Electronic Model 5400 with a hemisphere analyzer and a position sensitive detector. The spectrometer was equipped with a $\mathrm{Mg} / \mathrm{Ka}(1253.6 \mathrm{eV})$ achromatic X-ray source operated at a power of $400 \mathrm{~W}$ and a $45^{\circ}$ angle was used with the X-ray source. A pass energy of $89.45 \mathrm{eV}$ was chosen for all angle-dependent acquisitions. The spectrometer was typically run at $6.7 \times 10^{-7}$ Torr vacuum. A wide scan $(0-1000 \mathrm{eV})$ was recorded for each sample, and the information of different sample depth was obtained by extending the ion sputtering time.

Contact angles were measured with a JJC- I contact angle goniometer.

The membranes were cut into circular disks by using a sharp-edged stainless steel die with inner diameter of $20 \mathrm{~mm}$. The samples were dried in vacuum oven for $24 \mathrm{~h}$ to determine their dry weight $(W)$. Absorption of LPU membranes was determined by immersing the membranes in a baker of water for $24 \mathrm{~h}$. After wiping off the surface water with a piece of filter paper, its weight $\left(W_{1}\right)$ was determined. The water absorption (WS) of the membranes was calculated by

$$
W S=\left(W_{1}-W_{2}\right) / W \times 100 \%
$$

\section{Results and Discussions}

\subsection{Effects of Solvents on Morphology}

THF, dioxane and DMAc were employed as the solvent for preparing LPU, the ESEM morphology of LPU membranes prepared was shown in Figure 2. The membranes prepared from THF and Dioxane were very brittle, and easy for rupture to take place in the membranes. As shown in Figure 2, membranes prepared from different solvents displayed totally different morphology. LPU1-THF particles had the biggest dimension with about 10 $\mu \mathrm{m}$ in diameter; LPU1-dioxane had globular particles about $5 \mu \mathrm{m}$ in diameter, and the LPU1-DMAc had smallest diameter of about $2 \mu \mathrm{m}$ in grain shape. It was reported that PU from lignin and MDI in THF appeared as grain with dimension higher than $200 \mu \mathrm{m}$ [41]. In contrast, our research showed that LPU particles had much smaller particle size. This is because PEG was added into the system, so that the lignin hard segment was well dispersed into the soft segment and formed smaller domains.

Individual particles with relatively well defined boundary can be seen for the LPU1-THF membrane. In contrast, for the LPU1-DMAc membrane, no boundary is evident and the particles were dispersed in continuous phase instead. The particles of LPU1-dioxane were separated, but with less defined boundary in comparison with the LPU1-THF membrane. These morphological characteristics are consistent with the mechanical properties that the LPU1-DMAc membranes are the strongest, as shown in Table 1. Therefore, all of the samples in the following research were prepared by using DMAc as solvent.

The solvents used had different polarity and boiling point. The boiling point of THF, dioxane and DMAc is $65.4^{\circ} \mathrm{C}, 101^{\circ} \mathrm{C}, 166^{\circ} \mathrm{C}$, and the dielectric constant is $7.5,2.3$ and 36.7 , respectively, suggesting that DMAc had the highest polarity and dioxane the lowest. Our results indicate that higher polarity and higher boiling point were beneficial for the preparation of LPU particles with smaller size and stronger mechanical properties. However, as to dioxane which has higher boiling point and weaker polarity than THF, LPU showed smaller diameter, indicating boiling point acted as a predominant factor instead of polarity.

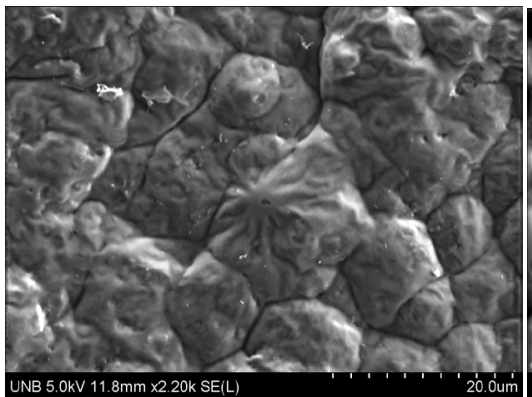

(a)

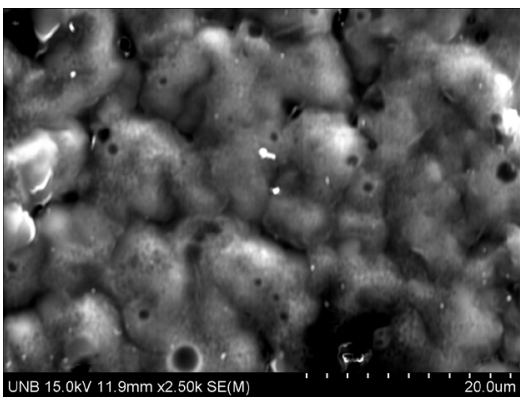

(b)

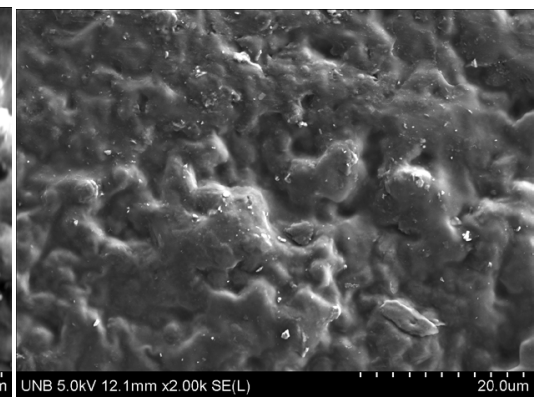

(c)

Figure 2. ESEM morphology of LPU1 membranes (a) prepared from THF (LPU1-THF); (b) prepared from dioxane (LPU1-dioxane); (c) prepared from DMAc (LPU1-DMAc). 


\subsection{Effects of Lignin on Morphology}

The morphology of LPU membranes with different lignin content was investigated. Figure 3(a) showed the results at 50\% AL content. In comparison with those in Figure 2(c), which were obtained at $43.3 \%$ AL content, one can find that the particles of LPU1 adhere to each other while boundary among particles became clear with the increase of lignin concentration. It can be postulated that lignin can disperse into polyurethane molecular chain well with lower concentration, as well as the interpenetration of polyurethanes into lignin domains. It is well understood that interpenetration plays a significant role in enhancing the compatibility of polymer since physical interlocking prohibits the phase separation [28]. As the lignin concentration increased, self-aggregate of star-like lignin was facilitated and resulted in many supramolecular domains, which displayed as separated oblate particles and suggested enhanced phase separation. This was consistence with tensile strength results; the membrane became brittle and weak with the further increase in lignin concentration.

\subsection{Effect of TMP Content on Morphology}

Different TMP content, namely 0\%, 2\% and 3\% was investigated and the ESEM morphology of LPU membranes was illustrated in Figure 2(c), Figure 3(b) and Figure 3(c), respectively. Increasing the TMP content from $0 \%$ to $2 \%$, the LPUT2 membrane became more homogeneous. The results can be explained by the hypothesis that the PU domains and lignin domains are interpenetrated into each other, due to the increased physical and chemical interlocks when two molecules are simultaneously crosslinked in the close vicinity of the other component [41]. This interlocks will minimize phase separation and improve the compatibility. As a result, the glass transition ( $\mathrm{Tg}$ ) of polymers is increased, and the mobility of the chain is decreased, which is in agreement with DMA results.

A further increase in the TMP content from 2\% to 3\%, Figure 3(c) showed that fewer particles were evident in comparison with Figure 3(b) (at a 2\% TMP content), further supporting the conclusion that the PU domains and lignin domains are interpenetrated into each other. However, Figure 3(c) showed that there are stress cracks at a 3\% TMP, also the LPU obtained had much lower strength properties, which may be caused by localized crosslinking.

\subsection{Crosslinking Density and Mechanical Properties}

PEG of different molecular weight was used to prepare LPU. It was found that LPU films derived from PEG200, PEG400 and PEG600 were very brittle and unable for tensile testing. However, continuous flexible film can be obtained with PEG1000 and PEG1500. And PEG1000 was utilized for all the other experiments since the tensile strength of LPU films produced from PEG1000 was higher than that of PEG1500, as shown in Table 2.

It can be also observed from Table 1 that the tensile strength increased to a maximum with the ratio of the NCO group to the $\mathrm{OH}$ of 1.7. It is well known that more crosslinking between -NCO and -OH and more effective hydrogen bond can be formed with a higher $\mathrm{NCO} / \mathrm{OH}$ ratio, resulting in stronger polyurethane network [23] [42]. PU with lower hydroxyl functionality displayed less elastic and more brittle since crosslinking process is formed within the isocyanate groups [23]. However, it is worth noting that it was impossible to test LPU4 membrane when $\mathrm{n}(\mathrm{NCO}) / \mathrm{n}(\mathrm{OH})$ was 2.2, since it was found to be brittle, which was different from pure PU. In gen-

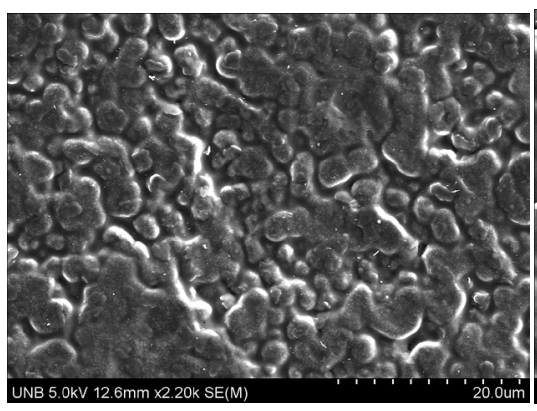

(a)

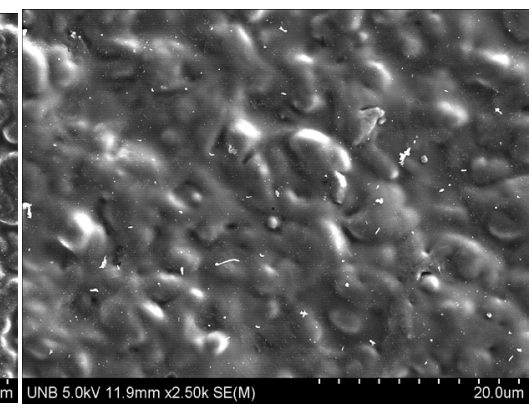

(b)

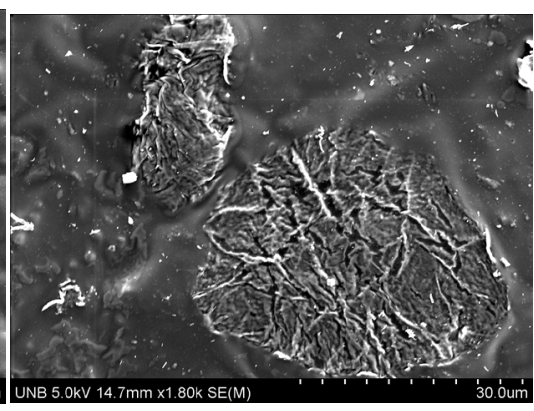

(c)

Figure 3. ESEM morphology of LPU membranes (a) LPU2; (b) LPUT2; (c) LPUT3. 
Table 2. Effects of lignin and TMP on crosslinking density.

\begin{tabular}{ccccccc}
\hline Sample & $V_{0}$ & $V$ & $v=V_{0} / V$ & $v 2$ & $v 1 / 3$ & $\begin{array}{c}\text { Crosslinking density } \\
\times 10^{-3} \mathrm{~mol}^{-\mathrm{cm}^{-3}}\end{array}$ \\
\hline PU & 18.308 & -- & -- & -- & -- & - \\
LPU1 & 21.949 & 73.359 & 0.29920 & 0.08952 & 0.66884 & 0.31024 \\
LPUT1 & 26.162 & 72.816 & 0.35929 & 0.12909 & 0.71091 & 0.55047 \\
LPUPT2 & 17.444 & 29.047 & 0.60054 & 0.36065 & 0.84369 & 3.33768 \\
LPUPT3 & 30.421 & 55.011 & 0.55299 & 0.30580 & 0.82080 & 2.42933 \\
\hline
\end{tabular}

eral, the inclusion of AL in the preparation of PU resulted in higher tensile strength can be obtained with the same $n(\mathrm{NCO}) / \mathrm{n}(\mathrm{OH})[43]$. This can be attributed to the introduction of AL.

The crosslinking density of LPU membranes with various AL and TMP contents was determined based on the swelling test in DMF, and the results are shown in Table 2. Without the addition of AL, the PU was totally dissolved in DMF, therefore no data can be obtained. For the addition of lignin, the LPU samples prepared swelled in DMF, however the original shape was retained. The swollen membranes still exhibit elastic and plastic behavior.

As shown in Table 2, the crosslinking density increased from $0.31 \times 10^{-3} \mathrm{~mol} \cdot \mathrm{cm}^{-3}$ to $3.34 \times 10^{-3} \mathrm{~mol} \cdot \mathrm{cm}^{-3}$ when increasing the TMP content from $0 \%$ to $2 \%$, resulting in more crosslinking points, as illustrated in Figure 1. But it decreased to $2.42 \times 10^{-3} \mathrm{~mol} \cdot \mathrm{cm}^{-3}$ when further increasing the TMP content to $3 \%$. Evidently the optimum TMP content was $2 \%$. The results in Table 1 showed that the PU membranes obtained under this condition (LPUT2) had the highest tensile strength.

\subsection{Dynamic Mechanical Properties of LPU Membranes}

The temperature dependences of storage modulus (G') and loss tangent $(\tan \delta)$ of PU and AL-containing PU (LPU1) were presented in Figure 4. The $\tan \delta$ peak is associated with the partial loosening of the polymer structure [43]. In general, the $\alpha$ relaxation is defined as the onset of long-range, coordinated molecular motion; while the $\beta$ transition is associated with the rotation of small side group such as methyl groups. The $\tan \delta$ curve of PU displayed two $\alpha$ relaxation at $-20.03^{\circ} \mathrm{C}$ and $28.85{ }^{\circ} \mathrm{C}$, which may be attributed to the glass transition temperature of the soft and hard segment, respectively. With the addition of AL, the two tan $\delta$ peaks merged together, resulting in a broadened peak at $0.28^{\circ} \mathrm{C}$, indicating that enhanced phase mixing process occurred when $\mathrm{AL}$ was added.

Shown in Figure 4 was also the higher storage modulus for LPU1 than for PU, which may be attributed to enhanced intermolecular interactions from the lignin. Furthermore, a new $\beta$ transition at $-77.61^{\circ} \mathrm{C}$ was seen for LPU1, which may be due to the rotation of side groups in lignin, as a result, the LPU1 sample can dissipate mechanical energy more effectively, thus, higher strength properties.

The temperature dependences of storage modulus (G') and loss tangent $(\tan \delta)$ of LPU1, LPUT1, LPUT2 and LPUT3 based at different TMP contents were illustrated in Figure 5. The glass transition temperature (Tg, $\alpha$ transition temperature) shifted from $0.28^{\circ} \mathrm{C}$ to $12.45^{\circ} \mathrm{C}$ when TMP content increased from $0 \%$ to $2 \%$, while the intensity of $\tan \delta$ peak also increased, suggesting that the thermal stability of LPU membranes increased with the increase in the TMP content. The increase in Tg also indicated that the mobility of chain for the phase separation was reduced. However, when the TMP content further increased to $3 \%$, the Tg decreased to $8.47^{\circ} \mathrm{C}$, suggesting the occurrence of enhanced phase separation, these results are consistent with the ESEM results, shown in Figure 3(c).

The storage modulus of the glassy state for LPU, LPUT1, LPUT2 and LPUT3 displayed similar values, indicating similar structure of the soft segments for all of the samples. On the other hand, an increase in the rubbery state modulus was evident when increasing the TMP content, which may be due to the increased crosslinking density. There is a reduction in the storage modulus for LPUT3 after the $\alpha$ transition. For copolymers with the same soft segment composition, the storage modulus is strongly dependent on the hard segment [44]. This above results further supported the conclusion that over-crosslinking occurred for LPUT3 due to the fact that TMP content is too high, resulting in the decrease in strength properties. 


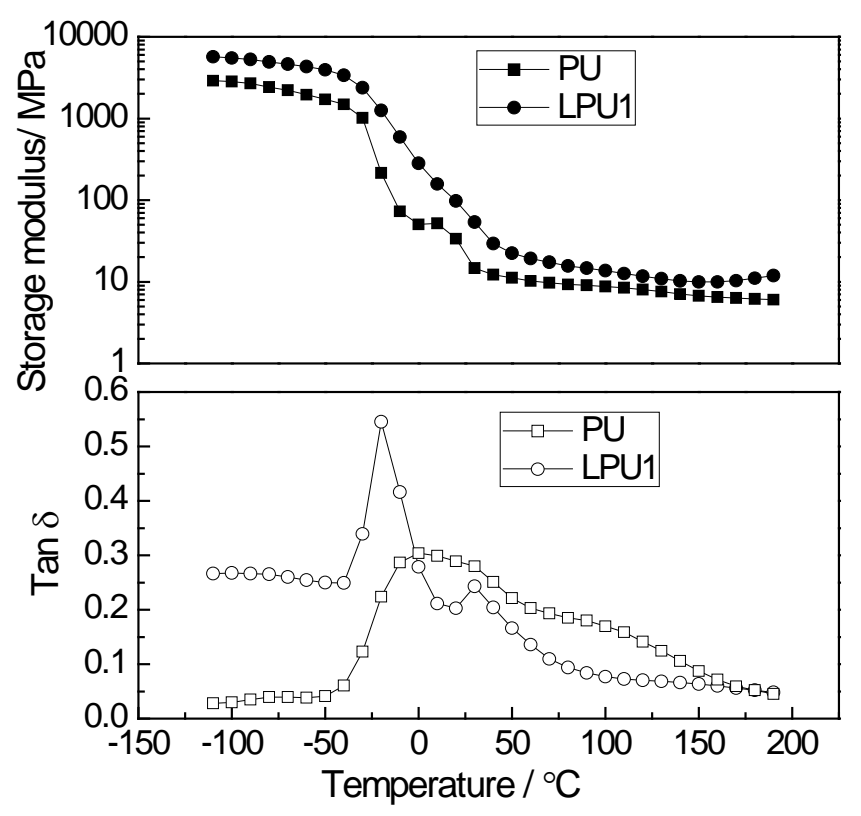

Figure 4. Temperature dependence of storage modulus and $\tan \delta$ for PU and LPU1.

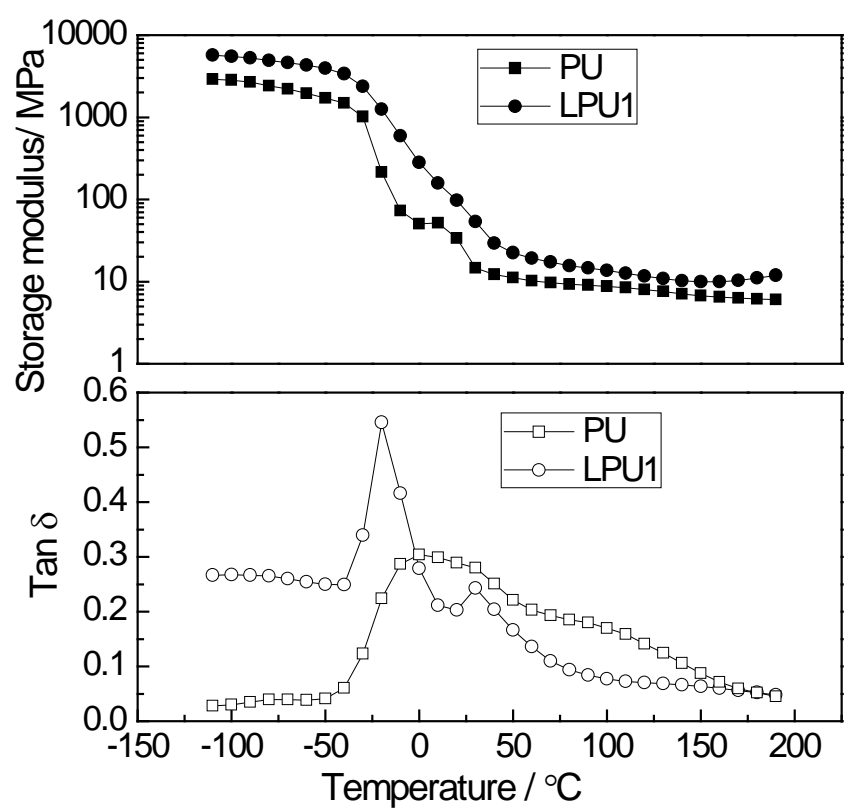

Figure 5. Temperature dependence of storage modulus and $\tan \delta$ for LPU1, LPUT1, LPUT2 and LPUT3.

\subsection{XPS Analysis}

The high C1s XPS spectra of the top and bottom surfaces of LPU membranes were shown in Figure 6. The peak area of carbons associated with different environment and peak area ratio from the deconvoluted spectra were shown in Table 3. Polyurethane is well known about its surface segregation characteristics [45] [46], it is reported that low surface energy soft segment resides towards the top surface and high surface energy urethane/urea component resides inside the bulk of the polymer [45] [46].

As shown in Table 3, higher $\mathrm{C}-\mathrm{O} /(\mathrm{C}-\mathrm{C} / \mathrm{C}-\mathrm{H})$ peak area ratios were found on the top surface than the bottom surface of PU membrane. Similar trend was also observed for other samples, supporting the conclusion that the 

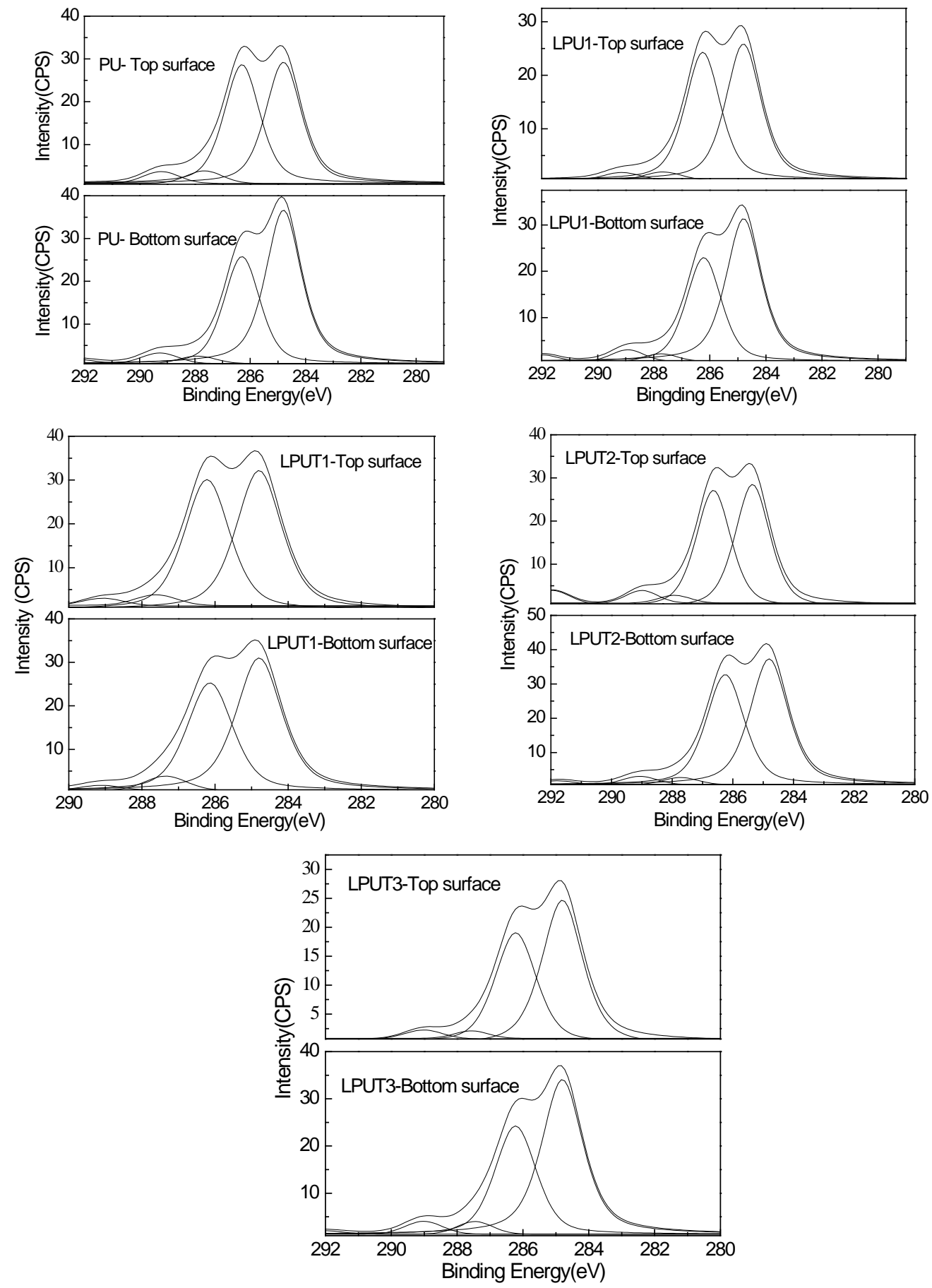

Figure 6. The XPS spectra for surface and bottom of LPU membranes.

soft segment preferentially aggregated on the top surface. It was also found that C-O (surface)/C-O (bottom) decreased from 1.243 to 1.225 with the addition of lignin. This can be due to phase mixing process due to the introduction of lignin. And with the introduction of TMP, the C-O (surface)/C-O (bottom) kept decreasing from 1.225 to 1.000 . In this research, the variation in the concentration of hard segment was achieved by changing lignin and TMP. It is apparent that the increase of lignin and TMP concentration results in the increase in the concentration of hard segment. So the results above suggested enhanced phase mixing and reduction in segregation behavior of high surface component with increased concentration of hard segment. 
However, larger C-O (surface)/C-O (bottom) of 1.091 with lower C-O/(C-C/C-H) for both surface and bottom was found for LPUT3. This can be explained by the heterogeneous morphology formed with increased TMP concentration, but to some extent, this data is not representative due to the heterogeneity.

\subsection{Water Resistance}

As shown in Table 1, the water resistance can be improved when AL and TMP were used, that is, an increase in the crosslinking density was beneficial for the enhancement of water resistance. However, the water resistance decreased for LPUP5 when the PEG molecular weight increased.

The results of contact angle of LPU membranes were shown in Figure 7. It can be seen that the contact angle increased with the increase of the lignin and TMP contents, which are in agreement with the water resistance results in Table 1.

Table 3. The de-convoluted C1s peak area associated with carbons of LPU membranes.

\begin{tabular}{|c|c|c|c|c|c|c|c|}
\hline Sample & $\begin{array}{c}\text { C-C/C-H } \\
\text { area\% }\end{array}$ & $\begin{array}{l}\mathrm{C}-\mathrm{O} \\
\text { area\% }\end{array}$ & $\begin{array}{l}\mathrm{C}-\mathrm{N} \\
\text { area\% }\end{array}$ & $\begin{array}{l}\mathrm{C}=\mathrm{O} \\
\text { area\% }\end{array}$ & $\begin{array}{c}\mathrm{C}-\mathrm{O} /(\mathrm{C}-\mathrm{C} / \mathrm{C}-\mathrm{H})(\mathrm{A}) \\
\text { (area ratio) }\end{array}$ & $\begin{array}{l}\text { A surface/ } \\
\text { A bottom }\end{array}$ & $\begin{array}{l}\text { C-O(surface)/ } \\
\text { C-O(bottom) }\end{array}$ \\
\hline PU-surface & 46.7 & 45.4 & 4.0 & 3.8 & 0.972 & 1.516 & 1.243 \\
\hline PU-bottom & 56.9 & 36.5 & 2.2 & 3.1 & 0.641 & & \\
\hline LPU1-surface & 49.7 & 45.7 & 2.4 & 2.2 & 0.919 & 1.375 & 1.225 \\
\hline LPU1-bottom & 55.8 & 37.3 & 2.1 & 3.2 & 0.668 & & \\
\hline LPUT1-surface & 49.8 & 45.4 & 2.8 & 2.0 & 0.911 & 1.186 & 1.107 \\
\hline LPUT1-bottom & 53.4 & 41.0 & 4.2 & 1.5 & 0.768 & & \\
\hline LPUT2-surface & 46.7 & 43.2 & 2.2 & 3.5 & 0.925 & 1.094 & 1.000 \\
\hline LPUT2-bottom & 51.1 & 43.2 & 2.1 & 2.4 & 0.845 & & \\
\hline LPUT3-surface & 56.3 & 39.4 & 1.8 & 2.5 & 0.700 & 1.092 & 1.091 \\
\hline LPUT3-bottom & 56.3 & 36.1 & 3.2 & 3.4 & 0.641 & & \\
\hline
\end{tabular}

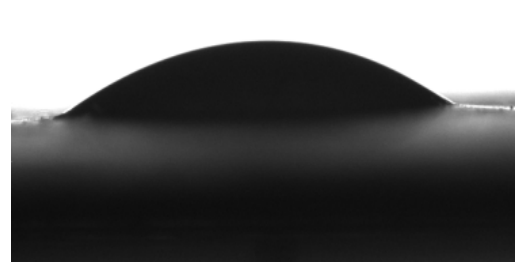

(a)

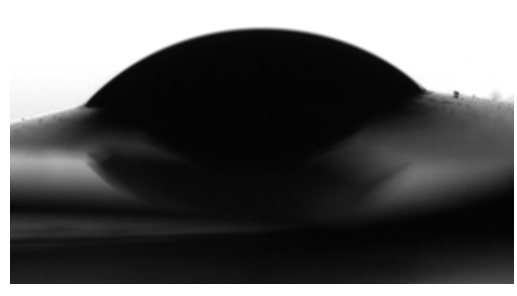

(b)

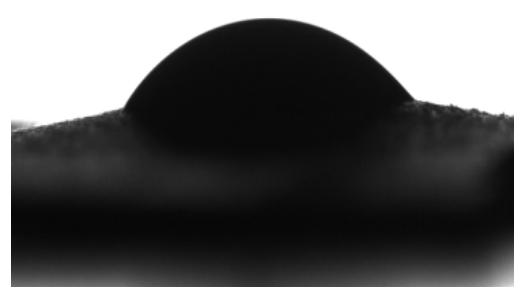

(c)

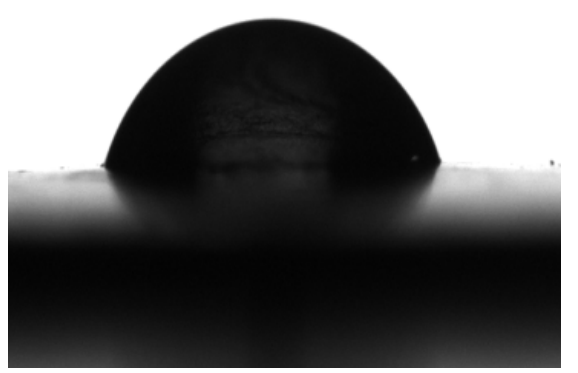

(d)

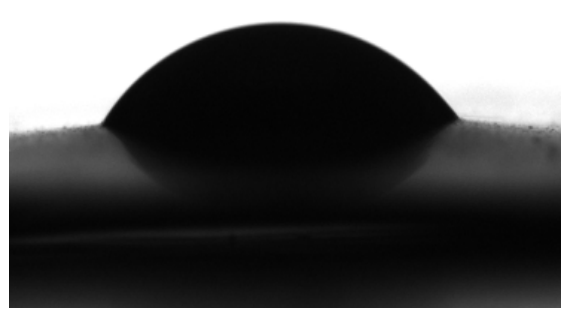

(e)

Figure 7. The contact angle photographs for PU and LPU membranes (a) PU (31.8 ); (b) LPU1 (38.1 ${ }^{\circ}$ ); (c) LPUT1 (47.3 $)$; (d) LPUT2 $\left(69.7^{\circ}\right)$; (e) LPUT3 $\left(51.6^{\circ}\right)$. 


\section{Conclusion}

Upon the addition of 2\% TMP crosslinking agent as a crosslinking agent, the acetic acid lignin (AL)-containing polyurethane membranes with good mechanical properties and water resistance can be obtained by copolymerization of MDI, PEG1000 and 43.3\% AL in DMAc as a solvent. The solvent with a strong polarity and higher boiling point was demonstrated to be beneficial for preparing AL-containing polyurethane. It was also found that the lignin domain can interpenetrate into polyurethane domain at the AL addition of 43.3\%, resulting in enhanced phase mixing, thus, higher mechanical properties, crosslinking density and water resistance in comparison with pure polyurethane. However, lignin self-aggregation was evident, when the lignin addition was $50.0 \%$. The addition of $2 \%$ TMP resulted in an increase in the crosslinking density (from $0.31 \times 10^{-3} \mathrm{~mol}^{\cdot} \mathrm{cm}^{-3}$ to $3.33 \times$ $10^{-3} \mathrm{~mol} \cdot \mathrm{cm}^{-3}$ ). Furthermore, the increase in the glass transition temperature, together with XPS results demonstrated enhanced phase mixing with increasing crosslinking density due to the addition of lignin and TMP, which is beneficial for improving mechanical properties and water resistance. While stress crack took place and lower mechanical property was detected when TMP concentration was greater than 3\%.

\section{Acknowledgements}

The authors express sincere thanks to National Natural Science Foundation of China (21204046), the ProjectSponsored by SRF for ROCS, SEM, the Science and Technology Research and Development Program of Shaanxi Province (Grant No. 2013KJXX-77) and the Project supported by the Key Laboratory of Education Bureau of Shaanxi Province (Grant No. 13JS018 and 2011JS057) for their financial support.

\section{References}

[1] Desai, S., Thakore, I.M., Sarawade, B.D. and Devi, S. (2000) Structure-Property Relationship in Polyurethane Elastomers Containing Starch as a Crosslinker. Polymer Engineering Science, 40, 1200-1210. http://dx.doi.org/10.1002/pen.11247

[2] Evtiouguina, M., Barros-Timmons, A., Cruz-Pinto, J.J., Pascoal Neto, C., Belgacem, M.N. and Gandini, A. (2002) Oxypropylation of Cork and the Use of the Ensuing Polyols in Polyurethane Formulations. Biomacromolecules, 3, 5762. http://dx.doi.org/10.1021/bm010100c

[3] Zhang, L.N. and Huang, J. (2001) Effects of Nitrolignin on Mechanical Properties of Polyurethane-Nitrolignin Films. Journal of Applied Polymer Science, 80, 1213-1219. http://dx.doi.org/10.1002/app.1206

[4] Lora, J.H. and Glasser, W.G. (2002) Recent Industrial Applications of Lignin: A Sustainable Alternative to Nonrenewable Materials. Journal of Polymers and the Environment, 10, 39-48. http://dx.doi.org/10.1023/A:1021070006895

[5] Zhao, X., Wu, R. and Liu, D. (2011) Production of Pulp, Ethanol and Lignin from Sugarcane Bagasse by Alkali-Peracetic Acid Delignification. Biomass Bioenergy, 35, 2874-2882. http://dx.doi.org/10.1016/j.biombioe.2011.03.033

[6] Ni, Y. and Hu, Q. (1995) Alcell Lignin Solubility in Ethanol-Water Mixtures. Journal of Applied Polymer Science, 57, 1441-1446. http://dx.doi.org/10.1002/app.1995.070571203

[7] Ni, Y.H. and Van Heiningen, A.R.P. (1996) Lignin Removal from Alcell ${ }^{\circledR}$ Pulp by Washing with Ethanol and Water. Tappi Journal, 79, 239-243.

[8] Pan, X. and Sano, Y. (2005) Fractionation of Wheat Straw by Atmospheric Acetic Acid Process. Bioresource Technology, 96, 1256-1263. http://dx.doi.org/10.1016/j.biortech.2004.10.018

[9] Jahan, M.S., Chowdhury, D.A.N. and Islam, M.K. (2007) Atmospheric Formic Acid Pulping and TCF Bleaching of Dhaincha (Sesbania aculeate), Kash (Saccharum spontaneum) and Banana Stem (Musa cavendish). Industrial Crops and Products, 26, 324-331. http://dx.doi.org/10.1016/j.indcrop.2007.03.012

[10] Cordeiro, N., Belgacem, M.N., Torres, I.C. and Moura, J.C.V.P. (2004) Chemical Composition and Pulping of Banana Pseudo-Stems. Industrial Crops and Products, 19, 147-154. http://dx.doi.org/10.1016/j.indcrop.2003.09.001

[11] Ligero, P., Villaverde, J.J., de Vega, A. and Bao, M. (2008) Delignification of Eucalyptus globulus Saplings in Two Organosolv Systems (Formic and Acetic Acid): Preliminary Analysis of Dissolved Lignins. Industrial Crops and Products, 27, 110-117. http://dx.doi.org/10.1016/j.indcrop.2007.08.008

[12] Ni, P. and Thring, R.W. (2003) Synthesis of Polyurethanes from Solvolysis Lignin Using a Polymerization Catalyst: Mechanical and Thermal Properties. International Journal of Polymeric Materials and Polymeric Biomaterials, 52, 685-707. http://dx.doi.org/10.1080/00914030304931

[13] Kubo, S. and Kadla, J.F. (2004) Poly(Ethylene oxide)/Organosolv Lignin Blends: Relationship between Thermal Pro- 
perties, Chemical Structure, and Blend Behavior. Macromolecules, 37, 6904-6911. http://dx.doi.org/10.1021/ma0490552

[14] Hatakeyama, T., Izuta, Y., Hirose, S. and Hatakeyama, H. (2002) Phase Transitions of Lignin-Based Polycaprolactones and Their Polyurethane Derivatives. Polymer, 43, 1177-1182. http://dx.doi.org/10.1016/S0032-3861(01)00714-5

[15] Hatakeyama, H. and Hatakeyama, T. (2005) Environmentally Compatible Hybrid-Type Polyurethane Foams Containing Saccharide and Lignin Components. Macromolecular Symposia, 224, 219-226. http://dx.doi.org/10.1002/masy.200550619

[16] Nadji, H., Bruzzèse, C., Belgacem, M.N., Benaboura, A. and Gandini, A. (2005) Oxypropylation of Lignins and Preparation of Rigid Polyurethane Foams from the Ensuing Polyols. Macromolecular Materials and Engineering, 290, 1009-1016. http://dx.doi.org/10.1002/mame.200500200

[17] Cui, G.J., Xia, W.B., Chen, G.J., Wei, M. and Huang, J. (2007) Enhanced Mechanical Performances of Waterborne Polyurethane Loaded with Lignosulfonate and Its Supramolecular Complexes. Journal of Applied Polymer Science, 106, 4257-4263. http://dx.doi.org/10.1002/app.27077

[18] Cateto, C.A., Barreiro, M.F., Rodrigues, A.E. and Belgacem, M.N. (2009) Optimization Study of Lignin Oxypropylation in View of the Preparation of Polyurethane Rigid Foams. Industrial \& Engineering Chemistry Research, 48, 25832589. http://dx.doi.org/10.1021/ie801251r

[19] Chuang, F.S. (2007) Analysis of Thermal Degradation of Diacetylene-Containing Polyurethane Copolymers. Polymer Degradation and Stability, 92, 1393-1407. http://dx.doi.org/10.1016/j.polymdegradstab.2007.02.020

[20] Pukánszky, B., Bagdi, K., Molnár, K. and Pukánnszky Jr., B. (2009) Thermal Analysis of the Structure of Segmented Polyurethane Elastomers: Relation to Mechanical Properties. Journal of Thermal Analysis and Calorimetry, 98, 825832. http://dx.doi.org/10.1007/s10973-009-0528-z

[21] Thring, R.W., Vanderlaan, M.N. and Griffin, S.L. (1997) Polyurethanes from Alcell ${ }^{\circledR}$ Lignin. Biomass and Bioenergy, 13, 125-132. http://dx.doi.org/10.1016/S0961-9534(97)00030-5

[22] Rials, T.G. and Glasser, W.G. (1986) Engineering Plastics from Lignin-XIII, Effect of Lignin Structure on Polyurethane Network Formation. Holzforschuang, 40, 353-360. http://dx.doi.org/10.1515/hfsg.1986.40.6.353

[23] Vanderlaan, M.N. and Thring, R.W. (1998) Polyurethanes from Alcell ${ }^{\circledR}$ Lignin Fractions Obtained by Sequential Solvent Extraction. Biomass and Bioenergy, 14, 525-531. http://dx.doi.org/10.1016/S0961-9534(97)10058-7

[24] Reimann, A., Mörck, R., Yoshida, H., Hatakeyama, H. and Kringstad, K.P. (1990) Kraft Lignin in Polyurethanes, Ш, Effects of the Molecular Weight of PEG on the Properties of Polyurethanes from a Kraft Lignin-PEG-MDI System. Journal of Applied Polymer Science, 41, 39-50. http://dx.doi.org/10.1002/app.1990.070410105

[25] Reimann, A., Mörck, H., Hatakeyama, H. and Kringstad, K.P. (1991) Effects of the Structure of Lignin on the Properties of Lignin-Based Polyurethanes. 6th International Symposium on Wood and Pulping Chemistry, Tianjin, 29 April-4 May 1991, 523.

[26] Velankar, S. and Cooper, S.L. (1998) Microphase Separation and Rheological Properties of Polyurethane Melets. 1. Effect of Block Length. Macromolecules, 31, 9181-9192. http://dx.doi.org/10.1021/ma9811472

[27] Hernandez, R., Weksler, J., Padsalgikar, A., Choi, T., Angelo, E., Lin, J.S., Xu, L.C., Siedlecki, C.A. and Runt, J, (2008) A Comparison of Phase Organization of Model Segmented Polyurethanes with Different Intersegment Compatibilities. Macromolecules, 41, 9767-9776. http://dx.doi.org/10.1021/ma8014454

[28] Lee, D.S. and Kim, S.C. (1984) Polyurethane Interpenetrating Polymer Networks (IPN’s) Synthesized under High Pressure. 1. Morphology and Tg Behavior of Polyurethane-Poly(Methyl methacrylate) IPN's. Macromolecules, 17, 268272. http://dx.doi.org/10.1021/ma00133a002

[29] Kubo, S. and Kadla, F. (2005) Hydrogen Bonding in Lignin: A Fourier Transform Infrared Model Compound Study. Biomacromolecules, 6, 2815-2821. http://dx.doi.org/10.1021/bm050288q

[30] Li, Y. and Sarkanen, S. (2002) Alkylated Kraft Lignin-Based Thermoplastic Blends with Aliphatic Polyesters. Macromolecules, 35, 9707-9715. http://dx.doi.org/10.1021/ma021124u

[31] Zhou, B., Zhou, A.S., Li, Y. and Feng, Y. (2009) Modified Polyurethane with Acetic Acid and Its Property. China Pulp and Paper, 28, 22-25.

[32] Li, Y., Aori, G.L., Sha, Z., Ma, X.J. and Zhou, B. (2008) Synthesis of Acetic Acid Lignin Polyurethane Foams. Transactions of China Pulp and Paper, 23, 55-59.

[33] Wang, P., Xie, Y.M., Aori, G.L., Zhan, H.Y. and Gan, D.N. (2004) Synthesis of Polyurethane from Acetic Acid Lignin and Its Properties. Chemistry and Industry of Forest Products, 24, 6.

[34] Wang, H.H., Ni, Y.H., Jahan, M.S., Liu, Z.H. and Schafer, T. (2010) Stability of Cross-Linked Acetic Acid LigninContaining Polyurethane. Journal of Thermal Analysis and Calorimetry, 103, 293-302. http://dx.doi.org/10.1007/s10973-010-1052-x 
[35] Kham, L., Bigot, Y.L., Mlayah, B.B. and Delmas, M. (2005) Bleaching of Solvent Delignified Wheat Straw Pulp. Appita Journal, 58, 135-137.

[36] Lam, H.Q., Bigot, Y.L., Delmas, M. and Avignon, G. (2001) Formic Acid Pulping of Rice Straw. Industrial Crops and Products, 14, 65-71. http://dx.doi.org/10.1016/S0926-6690(00)00089-3

[37] Cetin, N.S. and Ozmen, N. (2002) Use of Organosolv Lignin in Phenol-Formaldehyde Resins for Particleboard Production. I. Organosolv Lignin Modified Resins. International Journal of Adhesion and Adhesives, 22, 477-480.

[38] Kuho, S., Uraki, Y. and Sano, Y. (1998) Preparation of Carbon Fibers from Softwood Lignin by Atmospheric Acetic Acid Pulping. Carbon, 36, 1119-1124. http://dx.doi.org/10.1016/S0008-6223(98)00086-4

[39] Sarkar, S. and Adhikari, B. (2001) Synthesis and Characterization of Lignin-HTPB Copolyurethane. European Polymer Journal, 37, 1391-1401. http://dx.doi.org/10.1016/S0014-3057(00)00264-0

[40] Flory, P.J. and Rehner Jr., J. (1943) Statistical Mechanics of Cross-Linked Polymer Networks, II, Swelling. The Journal of Chemical Physics, 11, 521-536. http://dx.doi.org/10.1063/1.1723792

[41] Bonini, C., D’Auria, M., Emanuele, L., Ferri, R., Pucciariello, R. and Sabia, A.R. (2005) Polyurethanes and Polyesters from Lignin. Journal of Applied Polymer Science, 98, 1451-1456. http://dx.doi.org/10.1002/app.22277

[42] Li, X.R., Fei, G.Q. and Wang, H.H. (2006) Mechanical and Surface Properties of Membranes Prepared from Waterborne Cationic Hydroxyl-Terminated Polydimethylsiloxane/Polyurethane Surhfactant-Free Micro-Emulsion. Journal of Applied Polymer Science, 100, 40-46. http://dx.doi.org/10.1002/app.22524

[43] Ma, M.C.C., Wang, F.Y., Du, Y.C., Wu, C.L., Chiang, C.L. and Hung, A.Y.C. (2002) Intermolecular and Intramolecular Hydrogen Bonding of Poly(dimethylsiloxane)urethane-graft-poly(methyl methacrylate) Copolymers Based on 2,4-TDI and m-XDI. Journal of Applied Polymer Science, 86, 962-972. http://dx.doi.org/10.1002/app.11038

[44] Hernandez, R., Weksler, J., Padsalgikar, A. and Runt, J. (2007) Microstructural Organization of Three-Phase Polydimethylsiloxane-Based Segmented Polyurethanes. Macromolecules, 40, 5441-5449. http://dx.doi.org/10.1021/ma070767c

[45] Sreedhar, B., Chattopadhyay, D.K. and Swapna, V. (2006) Thermal and Surface Characterization of Polyurethane-Urea Clay Nanocomposite Coatings. Journal of Applied Polymer Science, 100, 2393-2401. http://dx.doi.org/10.1002/app.23140

[46] Chattopadhyay, D.K., Mishra, A.K., Sreedhar, B. and Raju, K.V.S.N. (2006) Thermal and Viscoelastic Properties of Polyurethane-Imide/Clay Hybrid Coatings. Polymer Degradation and Stability, 91, 1837-1849.

http://dx.doi.org/10.1016/j.polymdegradstab.2005.11.004 
Scientific Research Publishing (SCIRP) is one of the largest Open Access journal publishers. It is currently publishing more than 200 open access, online, peer-reviewed journals covering a wide range of academic disciplines. SCIRP serves the worldwide academic communities and contributes to the progress and application of science with its publication.

Other selected journals from SCIRP are listed as below. Submit your manuscript to us via either submit@scirp.org or Online Submission Portal.
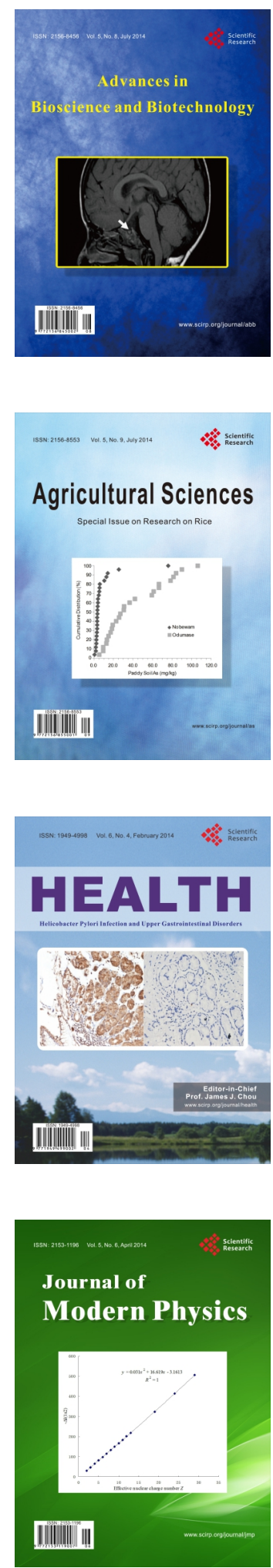
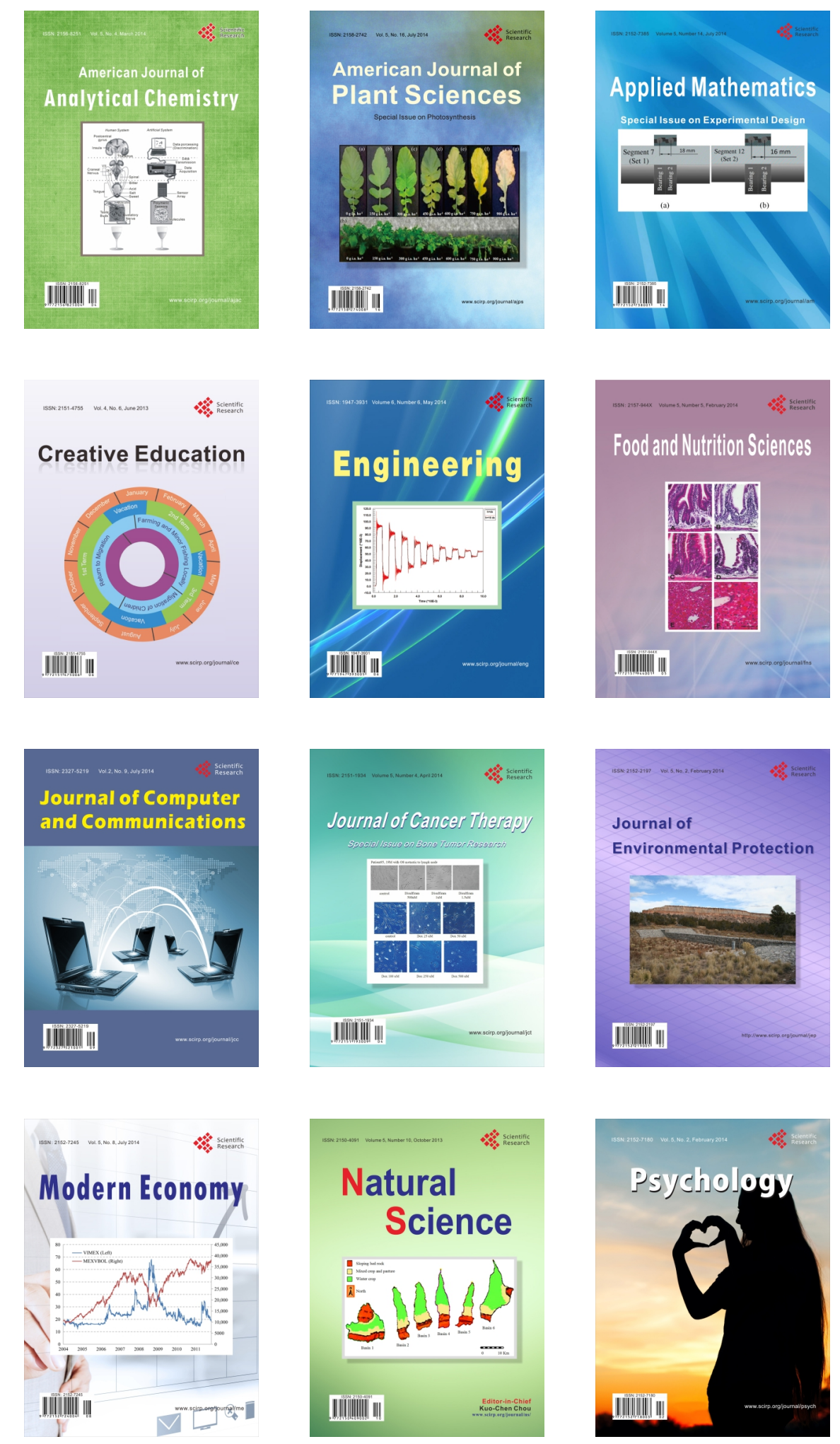